\title{
investigación
}

\section{MATERIALES DE CONSTRUCCION CON PROPIEDADES AISLANTES A BASE DE CASCARA DE ARROZ}

\author{
(BUILDING MATERIALS WITH INSULATING PROPERTIES BASED ON RICE HUSK)
}

Julián Salas Serrano,
Dr. Ingeniero Industrial (IETC.C-CSIC)

Janer Veras Castro,

Ingeniero Civil (Becario ICI-CSIC)

\section{RESUMEN}

El trabajo se enmarca en el provecto de investigación "Materiales, Tecnologias y. Prototipos de Viviendas de muy Bajo Coste”. Se pretende conseguir un material de construcción para su empleo como aislante térmico, a base de cemento y cáscara de arroz tratada.

Se analiza el comportamiento de distintas dosificaciones optando, en base a los resultados, por dos de ellas, con las que se realizaron paneles patrón de $60 \times 90 \times 6 \mathrm{~cm}$ que se ensavaron a flexión y se determinaron los valores de la conductividad térmica, valor de $\lambda$, que oscila entre 0,105 y 0,123.

Asimismo se trata de un conjunto de resultados parciales, de distintas aplicaciones, que se encuentran en proceso de resolución en el marco del estudio de hormigones pobres, especialmente pensados para su elaboración en paises en vias de desarrollo.

\section{SUMMARY}

This work within the research project "Material, Technologies and Low Cost Housing Prototypes" has the purpose to obtain a building material based on cement and treated rice husk, for its use as thermal insulator.

The p'rformance of different dosages was analyzed and according to the results two dosages were choosen to make standard panels of $60 \times 90 \times 6 \mathrm{~cm}$ which were tested for bending, and the thermal conductivity values were determined, lalue of $\lambda$, which fluctuale between 0,105 and 0,123.

It also deills with a whole of partial results, of div'rse applications, which are to be resolved within the frame-work of por concretes studi, pointing mainly for its elaboration in developing countries.

\section{INTRODUCCION *}

El trabajo que sigue se inscribe en el proyecto de investigación «Materiales, Tecnologías y Prototipos de Viviendas de Muy Bajo Coste» $\mathrm{y}$, más especificamente, en el objetivo de trabajo de dicho proyecto, que se ocupa de la utilización de la cáscara y paja de arroz como conglomerante y material aligerante del hormigón.

Valgan los resultados que siguen como primera aportación de posibles empleos de la cáscara de arroz (natural, tratada, molida o quemada) como material de construcción.

El planteamiento de partida del trabajo es el tratar de conseguir un material de construcción para su empleo como aislante térmico en el contexto de paises en vías de desarrollo con climas fundamentalmente cálidos. Se trata de buscar un material en el espíritu de las llamadas "tecnologias apropiadas", que, en base al cemento como conglomerante y a la cáscara de arroz como "árido ligero», permita sustituir con un balance técnico-económico positivo a otros materiales,

$\left(^{*}\right)$ Deseamos dejar constancia de nuestro agradecimiento por la valiosa información bibliográfica que nos facilitó al inicio del trabajo el Dr. Tortosa, del Instituto de Tecnologia de Alimentos del CSIC. generalmente importados. Se pretende pues conseguir un material que aun siendo inferior en resultados técnicos a las gamas actuales de poliuretanos, poliestirenos, fibras minerales, etc., permita perfilar una respuesta autóctona a ciertos problemas de aislamiento en construcción.

El perfil de "performances» del material que se busca (en base al cemento y a la cáscara), lo definimos aprioristicamente en la forma siguiente:

- Peso específico $(\gamma)$ comprendido entre $800 \div 1.200 \mathrm{~kg} / \mathrm{m}^{3}$.

- Coeficiente de conductividad $(\lambda)$ del orden de $0,15 \mathrm{kcal} / \mathrm{m} \mathrm{h}{ }^{\circ} \mathrm{C}$.

- Resistencia mecánica (compresión, flexión, tracción...) suficiente para asegurar su trabajabilidad, transporte, puesta en obra y uso en forma de elementos de pequeñas/medianas dimensiones. Esta resistencia estaria comprendida entre $20 \div 40 \mathrm{~kg} / \mathrm{cm}^{2}$.

- Debería ser fácilmente cortable y suficientemente resistente al fuego.

- Deberia presentar una adecuada respuesta al ataque de insectos, al contacto con el agua y a los ambientes climatológicos de características tropicales. 
- El proceso de producción de semiproductos (paneles, bloques u otros) deberá poder realizarse con materiales y medios propios de la construcción en PVD $(*)$.

La «universalidad» del arroz y, por consiguiente, de su cáscara es notoria en los PVD; su abundancia queda patente en el dato aportado por Mehta y Pitt (1), que estiman en $500 \times 10^{6}$ metros cúbicos la producción mundial de cáscara de arroz por año.

\section{CARACTERISTICAS FISICAS DE LA CASCARA DE ARROZ}

La cáscara de arroz empleada y, por tanto, a la que se refieren los valores que siguen, procede del molino «Divina Pastora» de Sueca (Valencia). El suministro se ha realizado en sacos de unos 8 a $10 \mathrm{~kg}$ de peso cada uno.

Uno de los primeros datos que necesitamos cuantificar es el peso especifico de esta materia prima. Hemos procedido a su determinación en las condiciones de "ambiente» de la nave de hormigonado del Instituto Eduardo Torroja, "suelto» y «compactado». También se ha determinado el peso específico "saturado seco» y la "absorción de agua».

\subsection{Pesos unitarios de la cáscara «suelta» y «compactada»}

Para su determinación, en condiciones ambientales, hemos definido un proceso sencillo y lo más universal posible.

Hemos partido de la utilización de un molde normalizado para probeta cilindrica de hormigón de $\varnothing 15 \times 30 \mathrm{~cm}$ de altura, lo que equivale a un volumen de $5.301,44 \mathrm{~cm}^{3}$.

La determinación del peso específico de la cáscara "suelta" se ha realizado vertiendo desde la boca del molde hasta llenarlo, procediendo con la barra de compactado en posición horizontal a su enrase. El peso del contenido se determinó con una balanza capaz de precisar $\pm 0,1 \mathrm{~g}$.

El peso específico medio de diez mediciones resultó ser de $121,5 \mathrm{~kg} / \mathrm{m}^{3}$.

Para la determinación del peso específico de la cáscara "compactada" hemos llenado el molde mediante tres tongadas (aproximadamente de un tercio del volumen total cada una), compactando mediante 25 golpes con barra de $\varnothing 15 \mathrm{~mm}$ y extremo esférico. El enrasado se hizo de la misma forma que en el caso anterior. El peso específico "compactado» medio resultó ser de $145,28 \mathrm{~kg} / \mathrm{m}^{3}$.

(*) PVD, abreviaturas empleadas para nominar genéricamente a los Paises en Vias de Desarrollo.
En forma idéntica se procedió con la cáscara tratada, a la que nos referiremos más adelante, resultando los siguientes valores medios de diez pruebas: peso especifico suelta: $118,10 \mathrm{~kg} / \mathrm{m}^{3}$; peso específico compactada: $167,68 \mathrm{~kg} / \mathrm{m}^{3}$.

\subsection{Peso específico de la cáscara «saturada seca» y absorción de agua de la cáscara}

Para la determinación de ambos valores hemos seguido básicamente la Norma UNE 7.140: «Determinación de los pesos específicos y absorción de agua en áridos finos». No obstante, por las características especificas de la cáscara de arroz, en su empleo como árido nos hemos apartado del contenido de esta norma en dos puntos concretos:

A. La cantidad de muestra de cáscara con superficie saturada seca, preparada de acuerdo con el Punto 4 de la norma citada, en lugar de ser de $500 \pm 0,1 \mathrm{~g}$ se ha tomado de $50 \pm 0,1 \mathrm{~g}$, ya que debido al bajo peso específico de la cáscara, un peso de $500 \mathrm{~g}$ haría muy dificil su manejo.

B. La determinación del peso total de agua añadida hasta conseguir un enrase en el matraz aforado de $500 \mathrm{~cm}^{3}$ resulta difícil, y por supuesto, fuera de la posibilidad de conseguir errores menores de 0,1 g como indica la norma. Esto se debe a que al flotar parcialmente la cáscara en el agua, incluso transcurrida la hora señalada por la norma, la determinación del plano de nivel resulta imprecisa.

Al objeto de paliar estos problemas, la medición se ha efectuado diez veces, encontrándose en la Tabla n. 1 los resultados de las mismas. Se han determinado los siguientes valores medios:

- Peso especifico aparente de la cáscara:

$$
X_{d}=\frac{G}{V-V_{1}}=453,1 \mathrm{~kg} / \mathrm{m}^{3}
$$

- Peso específico aparente de la cáscara saturada:

$$
X_{s}=\frac{P_{1}}{V-V_{1}}=787,2 \mathrm{~kg} / \mathrm{m}^{3}
$$

- Peso específico neto de la cáscara:

$$
X_{n}=\frac{G}{\left(V-V_{1}\right)-\left(P_{1}-G\right)}=690,3 \mathrm{~kg} / \mathrm{m}^{3}
$$

- Absorción de agua de la cáscara:

$$
A=\frac{P_{1}-G}{G} \cdot 100=73,70 \%
$$


Tabla n.o 1

DETERMINACION DE PESOS ESPECIFICOS DE LA CASCARA DE ARROZ

\begin{tabular}{|c|c|c|c|c|c|c|c|c|}
\hline $\begin{array}{c}\text { Medición } \\
\text { N.o }\end{array}$ & $\begin{array}{c}P_{1} \\
\text { Peso de muestra } \\
\text { con s.s.s. } \\
\text { (g) }\end{array}$ & $\begin{array}{c}\mathbf{V} \\
\text { Volumen } \\
\text { del matraz } \\
\left(\mathrm{cm}^{3}\right)\end{array}$ & $\begin{array}{c}V_{1} \\
\text { Volumen } \\
\text { de agua } \\
\text { añadida }\end{array}$ & $\begin{array}{c}\text { G } \\
\text { Peso muestra } \\
\text { seca }(48 \text { h a } \\
\left.110^{\circ} \mathrm{C}\right)\end{array}$ & $\mathbf{X}_{\mathbf{d}}=\frac{G}{\left(\mathbf{V}-\mathbf{V}_{\mathbf{l}}\right)}$ & $\mathbf{X}_{\mathbf{s}}=\frac{\mathbf{P}_{\mathbf{1}}}{\left(\mathbf{V}-\mathbf{V}_{\mathbf{l}}\right)}$ & $\mathbf{X}_{\mathrm{n}}=\frac{\mathbf{G}}{\left(\mathbf{V}-\mathbf{V}_{1}\right)-\left(\mathbf{P}_{1}-\mathbf{G}\right)}$ & $A=\frac{P_{1}-G}{G} \cdot 100$ \\
\hline 1 & 50 & 500 & 446,6 & 27,3 & 0,5112 & 0,9363 & 0,8893 & $83,15 \%$ \\
\hline 2 & 50 & 500 & 436,3 & 29,2 & 0,4584 & 0,7849 & 0,6807 & $71.23 \%$ \\
\hline 3 & 50 & 500 & 425,6 & 28,1 & 0,3777 & 0,6720 & 0,5352 & $78,21 \%$ \\
\hline 4 & 50 & 500 & 447,4 & 28,7 & 0,5456 & 0,9506 & 0,9169 & $74,22 \%$ \\
\hline 5 & 50 & 500 & 440,0 & 28,6 & 0,4767 & 0,8333 & 0,7409 & $74.83 \%$ \\
\hline 6 & 50 & 500 & 443,7 & 29,4 & 0,5222 & 0,8881 & 0,8235 & $70,07 \%$ \\
\hline 7 & 50 & 500 & 431,7 & 29,3 & 0,4290 & 0,7321 & 0,6155 & $70.65 \%$ \\
\hline 8 & 50 & 500 & 425,5 & 28,9 & 0,3879 & 0,6711 & 0,5412 & $76,36 \%$ \\
\hline 9 & 50 & 500 & 426,6 & 29,4 & 0,4005 & 0,6812 & 0,5568 & $70,07 \%$ \\
\hline 10 & 50 & 500 & 430,8 & 29,2 & 0,4220 & 0,7225 & 0,6033 & $71,23 \%$ \\
\hline \multicolumn{5}{|c|}{ VALORES MEDIOS } & 0,4531 & 0,7872 & 0,6903 & $73,70 \%$ \\
\hline
\end{tabular}

\subsection{Absorción debida a la humedad ambiente}

Se trata de un parámetro extraordinariamente cambiante al ser dependiente de las condiciones ambientales en las que se encuentre el material. Con carácter puramente informativo, para las condiciones de la nave de hormigonado del IETcc, el dia de toma de muestras se determinó un valor medio del $11,12 \%$.

\subsection{Granulometría y módulo de finura}

Para el análisis granulométrico se ha seguido el procedimiento corriente de tamizado. La muestra tomada ha sido, en los diez casos, de $180 \mathrm{~g}$ de cáscara en las condiciones de ambiente y se ha seguido el procedimiento de los cuantiles. Se adoptó esta cantidad por acomodarse bien al tamaño de los tamices normalizados.

Se empleó la serie de tamices Tyler constituida por los números: $4,8,16,30,50$ y 100 , con las aberturas que se indican en la Tabla n..$^{\circ}$. El tamizado se efectuó de manera mecánica haciendo uso del equipo adecuado para esta finalidad.

Los valores medios recogidos en la Tabla n. 2 y la figura 1, proporcionan las características granulométricas básicas de la cáscara de arroz. Puede señalarse que el 98,06\% del material se encuentra comprendido entre $0,59 \mathrm{~mm}$ (tamiz n. ${ }^{\circ} 30$ ) y $4,76 \mathrm{~mm}$ (tamiz n. ${ }^{\circ} 4$ ).

El módulo de finura o módulo granulométrico de un árido, en este caso cáscara, es igual a la centésima parte de la suma de los porcentajes acumulados retenidos en los tamices de la serie Tyler. En el caso estudiado el módulo de finura medio resultante es de 4,444 valor alto, si se compara con el de las arenas comunes, como consecuencia de la escasa proporción de componentes finos.

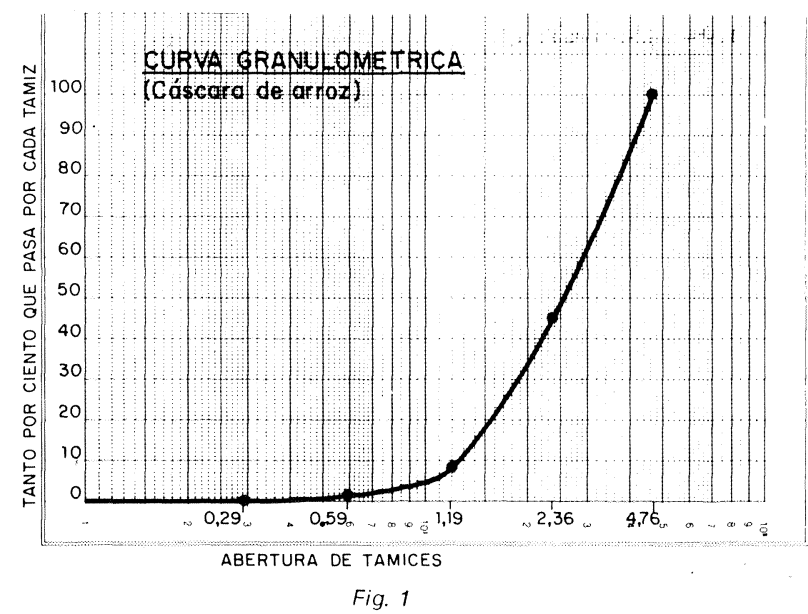


Tabla n.o 2

\begin{tabular}{|c|c|c|c|c|c|c|c|c|c|c|c|c|c|c|}
\hline \multirow{2}{*}{$\begin{array}{c}\text { Tamiz } \\
\text { N.० }\end{array}$} & \multirow{2}{*}{$\begin{array}{c}\text { Abertura } \\
(\mathrm{mm})\end{array}$} & \multicolumn{11}{|c|}{ CANTIDADES RETENIDAS POR LOS DISTINTOS TAMICES } & \multicolumn{2}{|c|}{ \% Retenido } \\
\hline & & 1 & 2 & 3 & 4 & 5 & 6 & 7 & 8 & 9 & 10 & Media & Parcial & $\Delta \mathbf{w}$ \\
\hline 4 & 4,76 & 0 & 0 & 0 & 0 & 0 & 0 & 0 & 0 & 0 & 0 & & 0,00 & 0,00 \\
\hline 8 & 2,38 & 90,50 & 99,50 & 98,50 & 102,50 & 95,80 & 107,50 & 95,20 & 92,00 & 106,00 & 108,80 & 99,63 & 55,48 & 55,48 \\
\hline 16 & 1,19 & 76,90 & 66,90 & 69,20 & 62,30 & 66,50 & 58,20 & 67,60 & 73,20 & 61,10 & 58,00 & 65,99 & 36,75 & 92,23 \\
\hline 30 & 0,59 & 8,90 & 9,90 & 9,60 & 11,00 & 12,20 & 10,00 & 12,30 & 11,30 & 9,90 & 9,60 & 10,47 & 5,83 & 98,06 \\
\hline 50 & 0,29 & 1,30 & 1,50 & 1,10 & 2,00 & 2,50 & 2,40 & 2,70 & 2,00 & 1,60 & 1,80 & 1,89 & 1,05 & 99,11 \\
\hline \multirow[t]{3}{*}{100} & $0,1 \dot{49}$ & 0,70 & 0,90 & 0,80 & 0,90 & 1,20 & 1,20 & 1,20 & 0,90 & 0,60 & 0,90 & 0,93 & 0,52 & 99,63 \\
\hline & FONDO & 0,70 & 0,90 & 0,60 & 0,60 & 0,80 & 0,50 & 0,70 & 0,50 & 0,60 & 0,70 & 0,66 & 0,37 & 100,00 \\
\hline & SUMA & 179,0 & 179,6 & 179,8 & 179,3 & 179,0 & 179,8 & 179,7 & 179,9 & 179,8 & 179,8 & 179,5 & 100,0 & 544,5 \\
\hline
\end{tabular}

Tabla n. ${ }^{\circ} 3$

DOSIFICACIONES TENTATIVAS

\begin{tabular}{|c|c|c|c|c|c|}
\hline & & $\begin{array}{c}\text { Cemento } \\
\mathbf{P}-350\end{array}$ & $\begin{array}{l}\text { Cáscara } \\
\text { de arroz }\end{array}$ & Agua & Totales \\
\hline \multirow{2}{*}{$\begin{array}{l}\text { Dosificación } n^{\circ} 1 \\
\frac{\mathrm{a}}{\mathrm{c}}=1,00\end{array}$} & $\begin{array}{c}\% \\
\text { de Peso } \\
\end{array}$ & $34,26 \%$ & $28,51 \%$ & $34,26 \%$ & $100,00 \%$ \\
\hline & $\begin{array}{c}\% \\
\text { Volumen } \\
\end{array}$ & $4,40 \%$ & $82,14 \%$ & $13,45 \%$ & $100,00 \%$ \\
\hline \multirow{2}{*}{$\begin{array}{l}\text { Dosificación } \mathrm{n} .{ }^{\circ} 2 \\
\frac{\mathrm{a}}{\mathrm{c}}=1,00\end{array}$} & $\begin{array}{c}\% \\
\text { Peso }\end{array}$ & $39,24 \%$ & $21,50 \%$ & $39,24 \%$ & $100,00 \%$ \\
\hline & $\begin{array}{c}\% \\
\text { Volumen } \\
\end{array}$ & $6,58 \%$ & $73,29 \%$ & $20,11 \%$ & $100,00 \%$ \\
\hline \multirow{2}{*}{$\begin{array}{l}\text { Dosificación n. }{ }^{\circ} 3 \\
\frac{\mathrm{a}}{\mathrm{c}}=0,80\end{array}$} & $\begin{array}{c}\% \\
\text { de Peso } \\
\end{array}$ & $45,32 \%$ & $19,35 \%$ & $35,32 \%$ & $100,00 \%$ \\
\hline & $\begin{array}{c}\% \% \\
\text { Volumen } \\
\end{array}$ & $8,30 \%$ & $71,95 \%$ & $19,74 \%$ & $100,00 \%$ \\
\hline \multirow{2}{*}{$\begin{array}{l}\text { Dosificación n.o } 4 \\
\frac{\mathrm{a}}{\mathrm{c}}=0,65\end{array}$} & $\begin{array}{c}\% \\
\text { de Peso } \\
\end{array}$ & $49,85 \%$ & $17,77 \%$ & $32,40 \%$ & $100,00 \%$ \\
\hline & $\%$ & $9,79 \%$ & $70,78 \%$ & $19,43 \%$ & $100,00 \%$ \\
\hline
\end{tabular}

\section{DOSIFICACIONES TENTATIVAS}

$\mathrm{Al}$ objeto de delimitar, en una primera aproximación, posibles dosificaciones adecuadas con el objeto perseguido, se optó por definir cuatro dosificaciones, que en adelante denominaremos números: $1,2,3$ y 4 , respectivamente. Todas a base de cáscara de arroz en estado ambiente, cemento PA-350 (con un $18 \%$ de adiciones puzolánicas) y agua.

De cada una de las cuatro amasadas se tomaron tres probetas de 7,5 $\times 15,0 \mathrm{~cm}$. Las razones que llevaron a adoptar estas probetas en lugar de la de $15,0 \times 30,0$ no son otras que facilitar el manejo, ahorrar material y que, al tratarse de un trabajo con fines poco estructurales, era menos necesario el empleo de probetas grandes, ya que éstas suponen un volumen de material unas ocho veces superior al de las empleadas.

Las dosificaciones se recogen en la Tabla n. ${ }^{\circ} 3$ y los resultados cuantitativos deducidos a tres, siete y sesenta días en la Tabla n. ${ }^{\circ} 4$.
La compactación en todos los casos fue manual mediante barra y el curado se realizó en cámara a $24 \pm 1{ }^{\circ} \mathrm{C}$ y $95 \%$ de humedad.

La ejecución de éstas y sucesivas probetas y el seguimiento de su evolución proporcionaron algunas enseñanzas especificas que nos parece oportuno comentar por tratarse de un material de ensayo relativamente poco divulgado.

Se optó por una compactación manual mediante barra al juzgar ésta como la más acorde con las condiciones de los PVD, aún conscientes de las fuertes dispersiones que ello podia suponer en el peso por probeta. Esta variación pudo cuantificarse posteriormente analizando los pesos de 37 probetas de la dosificación que denominaremos "patrón», realizadas por la misma persona. Los resultados del estudio estadístico confirmaron la hipótesis con un valor de la desviación típica de 44,01 y del rango de $175 \mathrm{~g}$, presentando pesos que oscilaban desde $427 \mathrm{~g}$ hasta un máximo de $602 \mathrm{~g}$.

La operación de rotura a compresión de probetas, al inicio de este trabajo, mostró de forma nítida cómo 
Tabla n. ${ }^{\circ} 4$

RESULTADOS DE LAS DOSIFICACIONES «TENTATIVAS» RESULTADO A TRES DIAS

\begin{tabular}{|c|c|c|c|c|c|c|c|}
\hline Dosificacion & $\begin{array}{c}\text { Peso al desmoldar } \\
\text { (g) }\end{array}$ & $\begin{array}{c}\text { Peso especifico } \\
\text { al desmoldar }\end{array}$ & $\begin{array}{c}\text { Peso al meter } \\
\text { en estufa }\end{array}$ & $\begin{array}{c}\text { Peso a las 72 } \\
\text { horas a 110 }{ }^{\circ} \mathbf{C}\end{array}$ & $\begin{array}{c}\text { Peso especifico } \\
\text { material seco }\end{array}$ & $\begin{array}{c}\text { Pérdida de peso } \\
\text { en \% }\end{array}$ & $\begin{array}{c}\text { Resistencia a } \\
\text { compresion }\end{array}$ \\
\hline 1 & 303,8 & 0,458 & 298,3 & 203,4 & 0,307 & $31,81 \%$ & $0,1 \mathrm{~kg} / \mathrm{cm}^{2}$ \\
\hline 2 & 494,5 & 0,746 & 487,2 & 301,6 & 0,455 & $31,10 \%$ \\
\hline 3 & 517,8 & 0,781 & 512,4 & 387,8 & 0,585 & $24,32 \%$ & $0,7 \mathrm{~kg} / \mathrm{cm}^{2}$ \\
\hline 4 & 652,5 & 0,984 & 638,5 & 434,7 & 0,656 & $31,92 \%$ \\
\hline
\end{tabular}

RESULTADO A SIETE DIAS

\begin{tabular}{|c|c|c|c|c|c|c|c|}
\hline Dosificación & $\begin{array}{c}\text { Peso al desmoldar } \\
\text { (g) }\end{array}$ & $\begin{array}{c}\text { Peso especifico } \\
\text { al desmoldar }\end{array}$ & $\begin{array}{c}\text { Peso al meter } \\
\text { en estufa }\end{array}$ & $\begin{array}{c}\text { Peso a las 72 } \\
\text { horas a 110 }{ }^{\circ} \mathrm{C}\end{array}$ & $\begin{array}{c}\text { Peso especifico } \\
\text { material seco }\end{array}$ & $\begin{array}{c}\text { Pérdida de peso } \\
\text { en \% }\end{array}$ & $\begin{array}{c}\text { Resistencia a } \\
\text { compresión }\end{array}$ \\
\hline 1 & 373,1 & 0,563 & 368,3 & 242,9 & 0,366 & $34,05 \%$ & $2,80 \mathrm{~kg} / \mathrm{cm}^{2}$ \\
\hline 2 & 516,7 & 0,779 & 510,4 & 314,4 & 0,474 & $38,50 \%$ & $15,84 \mathrm{~kg} / \mathrm{cm}^{2}$ \\
\hline 3 & 567,1 & 0,855 & 561,9 & 357,2 & 0,539 & $34,43 \%$ \\
\hline 4 & 656,0 & 0,989 & 647,3 & 436,8 & 0,659 & $32,52 \%$ & $38,03 \mathrm{~kg} / \mathrm{cm}^{2}$ \\
\hline
\end{tabular}

RESULTADO A SESENTA DIAS

\begin{tabular}{|c|c|c|c|c|c|c|c|}
\hline Dosificación & $\begin{array}{c}\text { Peso al desmoldar } \\
\text { (g) }\end{array}$ & $\begin{array}{c}\text { Peso especifico } \\
\text { al desmoldar }\end{array}$ & $\begin{array}{c}\text { Peso al meter } \\
\text { en estufa }\end{array}$ & $\begin{array}{c}\text { Peso a las 72 } \\
\text { horas a 110 }{ }^{\circ} \mathrm{C}\end{array}$ & $\begin{array}{c}\text { Peso especifico } \\
\text { material seco }\end{array}$ & $\begin{array}{c}\text { Pérdida de peso } \\
\text { en \% }\end{array}$ & $\begin{array}{c}\text { Resistencia a } \\
\text { compresion }\end{array}$ \\
\hline 1 & 472,2 & 0,7126 & 466,2 & 251,1 & 0,3789 & $46,18 \%$ & $11,77 \mathrm{~kg} / \mathrm{cm}^{2}$ \\
\hline 2 & 577,4 & 0,8713 & 571,4 & 335,9 & 0,5069 & $41,48 \%$ & $42,10 \mathrm{~kg} / \mathrm{cm}^{2}$ \\
\hline 3 & 625,3 & 0,9436 & 621,1 & 381,0 & 0,5749 & $38,66 \%$ & $59,75 \mathrm{~kg} / \mathrm{cm}^{2}$ \\
\hline 4 & 675,4 & 1,092 & 670,4 & 438,1 & 0,6611 & $34,65 \%$ & $71,53 \mathrm{~kg} / \mathrm{cm}^{2}$ \\
\hline
\end{tabular}

ésta se iniciaba en el tercio superior de la misma, por ser ésta la parte menos compactada. Para subsanar esta circunstancia acoplamos a los moldes un collarín de $\varnothing 7,5 \mathrm{~cm}$ y $5 \mathrm{~cm}$ de altura, que fijado sobre el molde metálico permitió conseguir una compactación manual más homogénea. Pese a ello, se presenta la dispersión de valores ya comentados en el párrafo anterior.

Otro imprevisto detectado en el proceso fue la aparición sobre las probetas de eflorescencias orgánicas cuando éstas permanecian varios dias en el ambiente normalizado de la cámara de curado $\left(23 \pm 1{ }^{\circ} \mathrm{C}\right.$ y $95 \%$ de humedad). El fenómeno no se da en probetas con cáscara de arroz tratada con cal, tratamiento que tomamos de Lemus (5), (Fig. 2).

A la vista de los resultados de los ensayos que se detallan en la Tabla n. 4 y figura 2 , teniendo presentes las cantidades de cemento empleadas en las cuatro dosificaciones y los valores propuestos por J. A. Aguirre y P. F. Sierra (6), nos decantamos por considerar como dosificación "patrón" o de referencia una de valores muy cercanos a la dosificación 3 , constituida por:

- $267 \mathrm{~kg}$ de cemento PA-350;

- $141,38 \mathrm{~kg}$ de cascarilla «ambiente»;

- 201,58 1 de agua para una relación $\mathrm{a} / \mathrm{c}=0,75$.

Tomando como pesos unitarios sin compactar (materiales sueltos) $1.328 \mathrm{~kg} / \mathrm{m}^{3}$ para el cemento
Tabla n. ${ }^{\circ} 5$

\begin{tabular}{|c|c|c|c|c|}
\hline & $\begin{array}{c}\text { Cemento } \\
\text { P-350 }\end{array}$ & $\begin{array}{l}\text { Cáscara de } \\
\text { arroz } \\
\text { ambiente }\end{array}$ & Total & $\begin{array}{c}\text { Relación } \\
\mathrm{a} / \mathrm{c}\end{array}$ \\
\hline \multirow{2}{*}{$\begin{array}{c}\text { Peso } \\
\left(\text { por } \mathrm{m}^{3}\right)\end{array}$} & $267,0 \mathrm{~kg}$ & $141,38 \mathrm{~kg}$ & 408,38 & \multirow[b]{2}{*}{0,755} \\
\hline & $65,38 \%$ & $34,62 \%$ & $100 \%$ & \\
\hline \multirow{2}{*}{$\begin{array}{l}\text { Volumen } \\
\left(\text { por } \mathrm{m}^{3}\right)\end{array}$} & $201,0 \mathrm{dm}^{3}$ & $1163,6 \mathrm{dm}^{3}$ & $1364,6 \mathrm{dm}^{3}$ & \\
\hline & $14,73 \%$ & $85,27 \%$ & $100 \%$ & \\
\hline
\end{tabular}

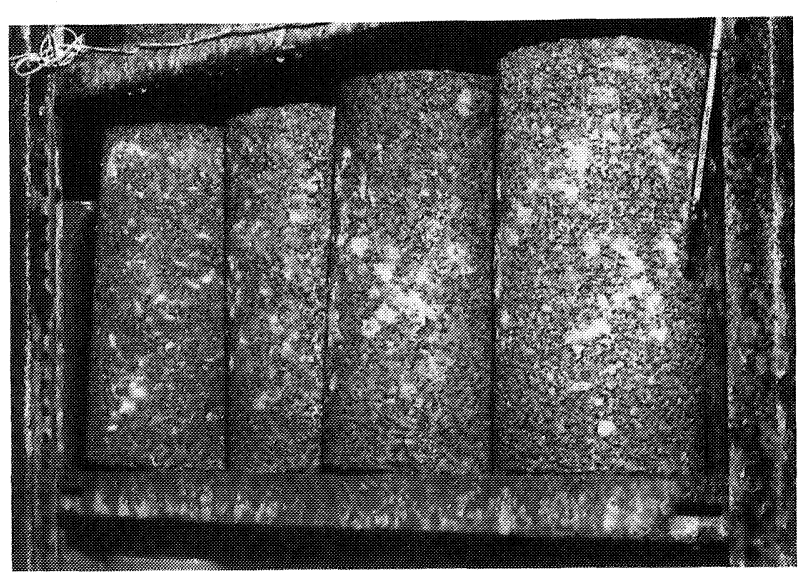

Fig. 2 
y $121,5 \mathrm{~kg} / \mathrm{m}^{3}$ para la cascarilla en estado ambiente. En volumen, la dosificación "patrón» resulta en material suelto de $201,0 \mathrm{dm}^{3}$ de cemento por $1.163,6 \mathrm{dm}^{3}$ de cascarilla, lo que supone un $85,27 \%$ de cáscara por un $14,73 \%$ de cemento. (Ver Tabla n. ${ }^{\circ}$ 5). La dosificación "patrón» en peso de materiales sueltos resultó ser: $65,38 \%$ de cemento y $34,62 \%$ de cáscara.

\section{OTRAS DOSIFICACIONES REALIZADAS}

Partiendo de la dosificación "patrón» se plantearon dos con valores simétricos de aquella que llamaremos « $\mathrm{A} » \mathrm{y}$ « $\mathrm{B} »$, resultando de aumentar y disminuir un $10 \%$ respectivamente la cantidad de cemento de la «patrón». Los valores de las mismas se recogen en la Tabla 6.

Por otra parte, al objeto de iniciar la utilización de la cáscara tratada con cal, se plantearon las dosificaciones «F», «G» $y$ «L». En todas ellas se preparó una disolución acuosa al $5 \%$ en peso de cal y se dejó la cáscara 24 horas procediéndose a remover varias veces en este periodo. Posteriormente, la cáscara se secó hasta conseguir la situación de "superficie saturada seca» (s.s.s.).

Las probetas realizadas empleando cáscara tratada con cal no presentaron durante el proceso de curado las eflorescencias orgánicas ya comentadas.

Finalmente, y a efectos de determinar el coeficiente de equivalencia entre los resultados obtenidos en las probetas de $7,5 \times 15 \mathrm{~cm}$ y de $15 \times 30 \mathrm{~cm}$, se procedió a la ejecución de probetas «QG» $\mathrm{y}$ "QP », grandes y pequeñas respectivamente con la misma dosificación patrón, para lo que, utilizando la misma amasada y forma de compactación, se alternó la confección de probetas grandes y pequeñas.

Los datos relativos a la evolución y resultados de ensayos de las dosificaciones mencionadas se recogen en las respectivas figuras 3 a 8 , en las que se recogen los siguientes datos:

- Resistencias a compresión a 3, 7, 28 y 60 dias.

- Valores medios de las resistencias a compresión.

- Humedades relativas al romper y valores medios.

- Peso de las probetas al romper y peso específico medio del conjunto de probetas.

A la vista de los valores tabulados y del gráficoresumen de la figura 9, cada uno de cuyos puntos corresponde a una serie de tres valores, se concluye los siguiente:

A. La dosificación «B» supone un ahorro de $10 \%$ en peso de cemento respecto de la "patrón» pero una caída de resistencias que la invalidan para su utilización. El incremento de un $10 \%$ de cemento respecto de la "patrón», dosificación «A», aporta ligeros incrementos en las resistencias a 3 y 7 días pero proporciona valores sensiblemente inferiores a 28 y 60 días a los de la "patrón». A la vista de los resultados se concluye que para cáscara sin tratar, la dosificación "patrón» se perfila como la idónea para los fines perseguidos de este trabajo.

Tabla n.o 6

\begin{tabular}{|c|c|c|c|c|c|}
\hline \multirow{2}{*}{ Nomenclatura } & \multicolumn{4}{|c|}{ DOSIFICACION } & \\
\hline & Cemento & Cáscara & Agua & Relación a/c & \\
\hline $\begin{array}{c}\text { Patrón } \\
\mathrm{P}\end{array}$ & $\begin{array}{r}\text { PA-350 } \\
43,77 \% \\
4,57 \mathrm{~kg}\end{array}$ & $\begin{array}{l}\text { Ambiente } \\
23,18 \% \\
2,42 \mathrm{~kg}\end{array}$ & $\begin{array}{c}33,04 \% \\
3,451\end{array}$ & 0,755 & $\begin{array}{l}\text { Se ha adoptado esta dosificación como } \\
\text { patrón a efectos comparativos. }\end{array}$ \\
\hline $\mathbf{A}$ & $\begin{array}{r}\text { PA-350 } \\
46,75 \% \\
5,05 \mathrm{~kg}\end{array}$ & $\begin{array}{l}\text { Ambiente } \\
17,96 \% \\
1,94 \mathrm{~kg}\end{array}$ & $\begin{array}{c}35,27 \% \\
3,81\end{array}$ & 0,755 & $\begin{array}{l}\text { Partiendo de la patrón y manteniendo } \\
\text { igual relación a/c se aumenta un } 10 \% \text { en } \\
\text { peso de cemento disminuyendo la cásca- } \\
\text { ra en igual peso. }\end{array}$ \\
\hline B & $\begin{array}{r}\text { PA-350 } \\
40,73 \% \\
4,11 \mathrm{~kg}\end{array}$ & $\begin{array}{l}\text { Ambiente } \\
28,54 \% \\
2,88 \mathrm{~kg}\end{array}$ & $\begin{array}{c}31,28 \% \\
3,451\end{array}$ & 0,755 & $\begin{array}{l}\text { Partiendo de la patrón y manteniendo } \\
\text { igual relación a/c se disminuye un } 10 \% \\
\text { el peso de cemento y se aumenta la cás- } \\
\text { cara en igual proporción. }\end{array}$ \\
\hline F & $\begin{array}{c}\text { PA-350 } \\
43,77 \% \\
4,57 \mathrm{~kg}\end{array}$ & $\begin{array}{c}\text { s.s.s. en disolución } \\
\text { de cal } \\
23,18 \% \\
2,42 \mathrm{~kg} \\
\end{array}$ & $\begin{array}{c}33,04 \% \\
3,451\end{array}$ & 0,755 & $\begin{array}{l}\text { Con cáscara tratada en disolución de cal } \\
\text { al } 5 \% \text { en agua, se seca la cáscara hasta } \\
\text { s.s.s. y se reproduce la patrón. }\end{array}$ \\
\hline G & $\begin{array}{l}\text { PA-350 } \\
48,43 \% \\
6,97 \mathrm{~kg}\end{array}$ & $\begin{array}{c}\text { s.s.s. en disolución } \\
\text { de cal } \\
25,64 \% \\
3,69 \mathrm{~kg}\end{array}$ & $\begin{array}{c}25,92 \% \\
3,731\end{array}$ & 0,535 & $\begin{array}{l}\text { Con cáscara tratada en disolución de cal } \\
\text { al } 5 \% \text { en agua, se seca hasta s.s.s., se au- } \\
\text { menta un } 10 \% \text { en peso el cemento y la } \\
\text { cáscara de la patrón, disminuyendo el } \\
\text { agua un } 20 \% \text {. }\end{array}$ \\
\hline $\mathrm{L}$ & $\begin{array}{l}\text { PA-350 } \\
46,75 \% \\
5,05 \mathrm{~kg}\end{array}$ & $\begin{array}{c}\text { s.s.s. en disolución } \\
\text { de cal } \\
17,96 \% \\
1,94 \mathrm{~kg}\end{array}$ & $\begin{array}{c}35,27 \% \\
3,811\end{array}$ & 0,755 & $\begin{array}{l}\text { Repetir la dosificación A pero con cásca- } \\
\text { ra tratada con cal y en estado de s.s.s. }\end{array}$ \\
\hline $\begin{array}{l}\text { Contraste de probetas } \\
7,5 \times 15 \text { y } 15 \times 30 \\
\text { QG-1 a } 8 \\
\text { QP-1 a } 9 \\
\text { Panel } 90 \times 60 \times 6 \mathrm{~cm}\end{array}$ & $28,55 \mathrm{~kg}$ & $\begin{array}{l}\text { Ambiente } \\
23,18 \% \\
15,13 \mathrm{~kg}\end{array}$ & $\begin{array}{l}33,04 \% \\
21,571\end{array}$ & 0,755 & $\begin{array}{l}\text { Se reproduce la dosificación patron a } \\
\text { efectos de contraste por la influencia del } \\
\text { tamaño de las probetas. }\end{array}$ \\
\hline
\end{tabular}



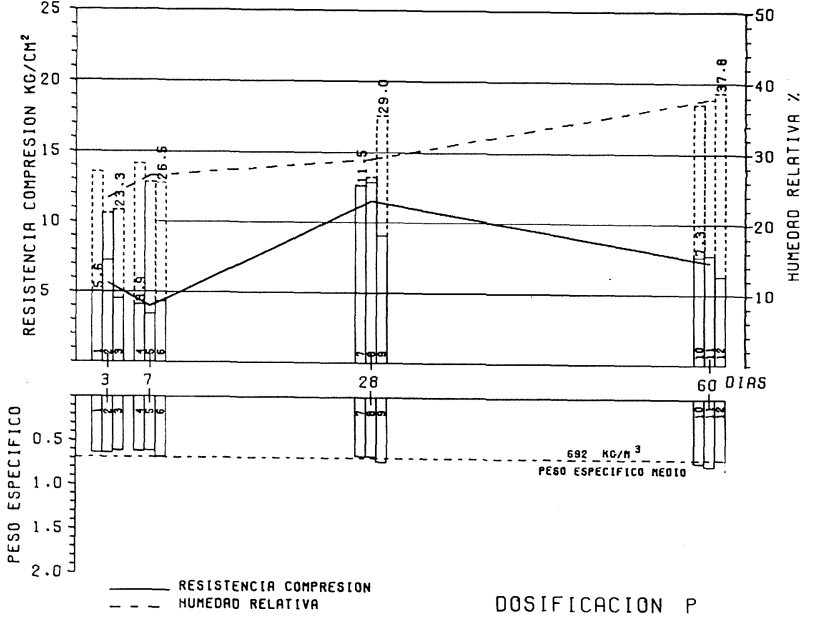

Fig. 3
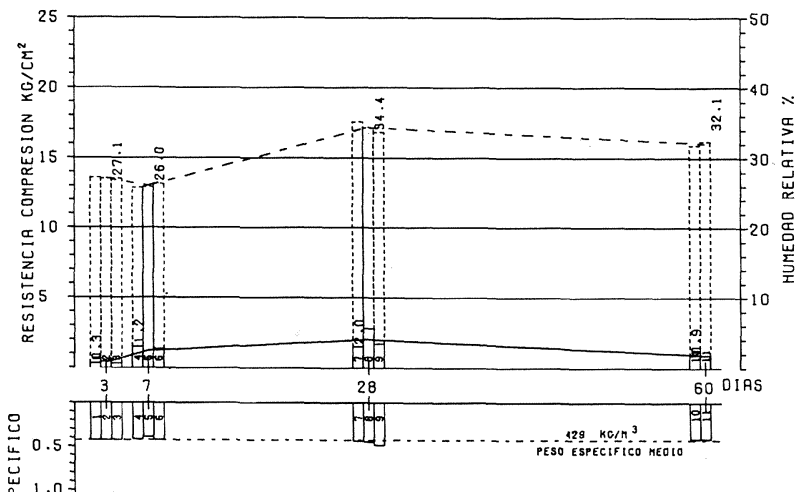

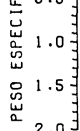

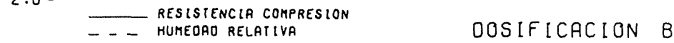

Fig. 5
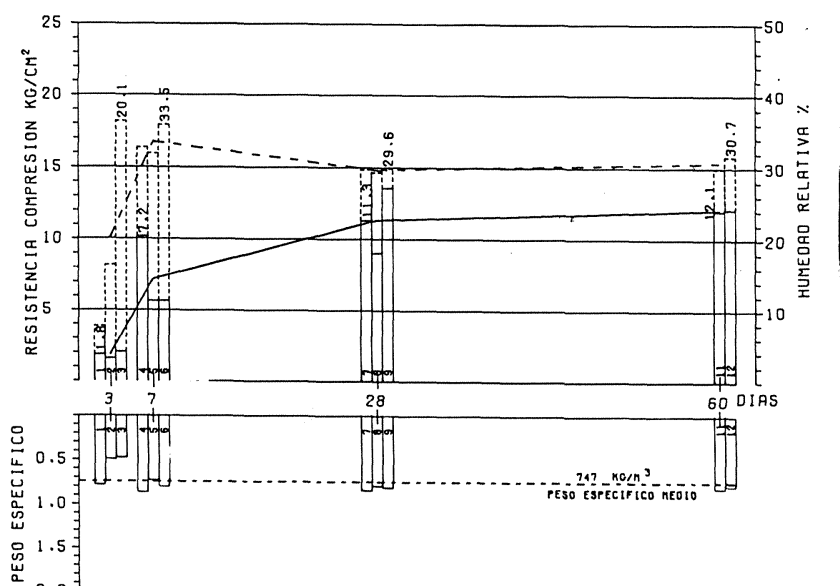

$$
\begin{aligned}
& \text { RESTSTENCLA COMPRESION } \\
& --- \text { HUMEOAO RELATIVA. }
\end{aligned}
$$

DOSIFICACION G

Fig. 7
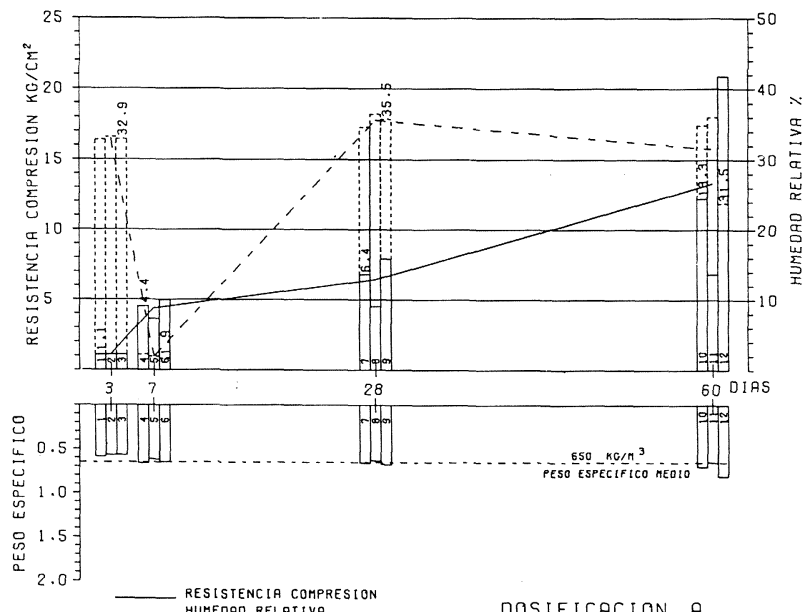

Fig. 4
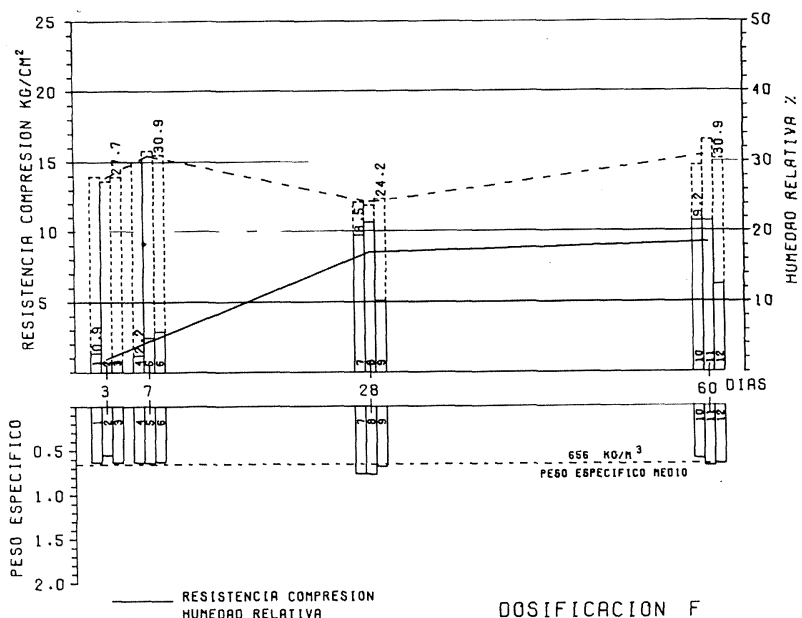

Fig. 6

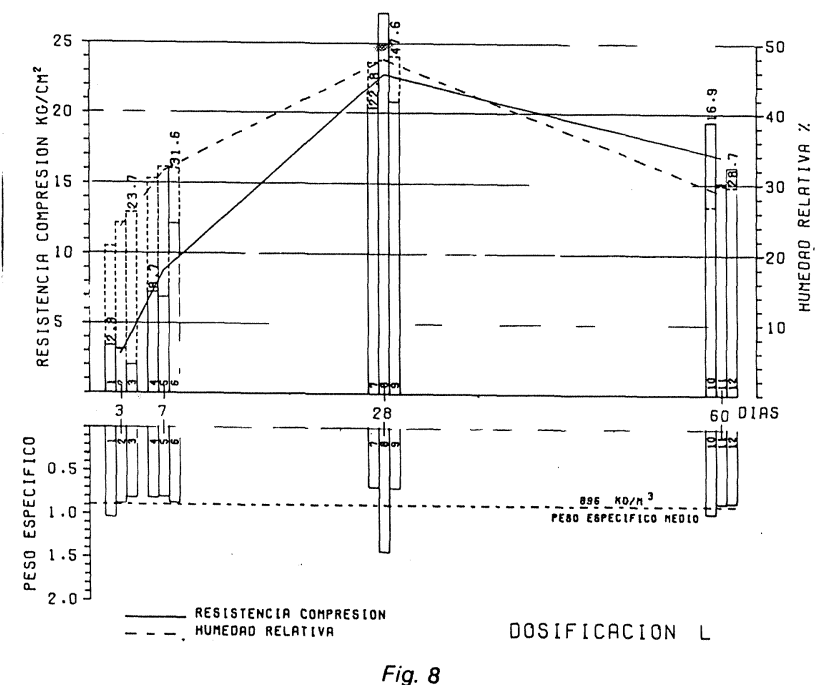

Fig. 8 


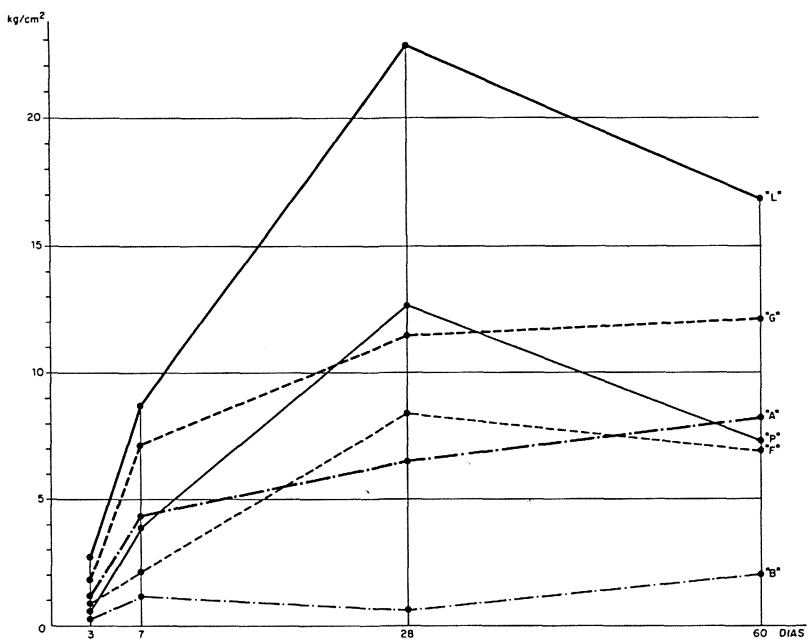

Fig. 9

B. En los casos de las dosificaciones «F», «G» "L", todas empleando cáscara tratada con cal, resulta evidente: que la «F» (idéntica a la «patrón», sólo que con cascarilla tratada con cal), porporciona resistencias muy por debajo de la "patrón». Que la "G» presenta resistencias considerables que estimamos se deben a la baja sensible de 0,755 a 0,535 en la relación agua/ cemento. Finalmente, es notorio el excelente comportamiento de la dosificación "L» que, con igual cantidad de cemento, duplica prácticamente las resistencias obtenidas por la dosificación " $\mathrm{A}$ » a todas las edades.

C. En base a las conclusiones anteriores se decidió estudiar dos series de probetas con dosificaciones "patrón» $\mathrm{y}$ «L», modificando únicamente la relación agua/cemento que se fijó en: $0,50 \mathrm{y}$ 0,60 respectivamente.

D. Se moldearon paneles de las cuatro dosificaciones seleccionadas, al objeto de determinar el comportamiento resistente y aislante de los mismos, en la forma que se detalla en los Apartados 5 y 6 que siguen.

E. Se detecta en los casos de-las dosificaciones «L», "patrón» $\mathrm{y}$ « $\mathrm{F}$ » una caída de resistencia al pasar de 28 días a 60 manteniendo el curado en cámara, lo cual es un problema que debe ser estudiado.

\section{DOSIFICACIONES DE CORRECCION AGUA/CEMENTO}

A la vista de los resultados de resistencia a compresión (ver Fig. 9), se procedió a determinar la posible influencia que sobre las dosificaciones "patrón» y «L» podian suponer pequeñas variaciones de la relación agua/cemento.

Se realizaron doce probetas $7,5 \times 15 \mathrm{~cm}$ para relaciones agua/cemento de $0,50,0,60$ y 0,85 respectivamente, que nominaremos en adelante como:
P50, P60, P85, L50, L60 y L85. Igualmente, de cada una de las seis dosificaciones mencionadas se confeccionaron paneles de $60 \times 60 \times 6 \mathrm{~cm}$ a efectos de determinar el valor de $\lambda$; no fue posible el desmoldeo de los elementos P50 que claramente rompieron por falta de resistencia.
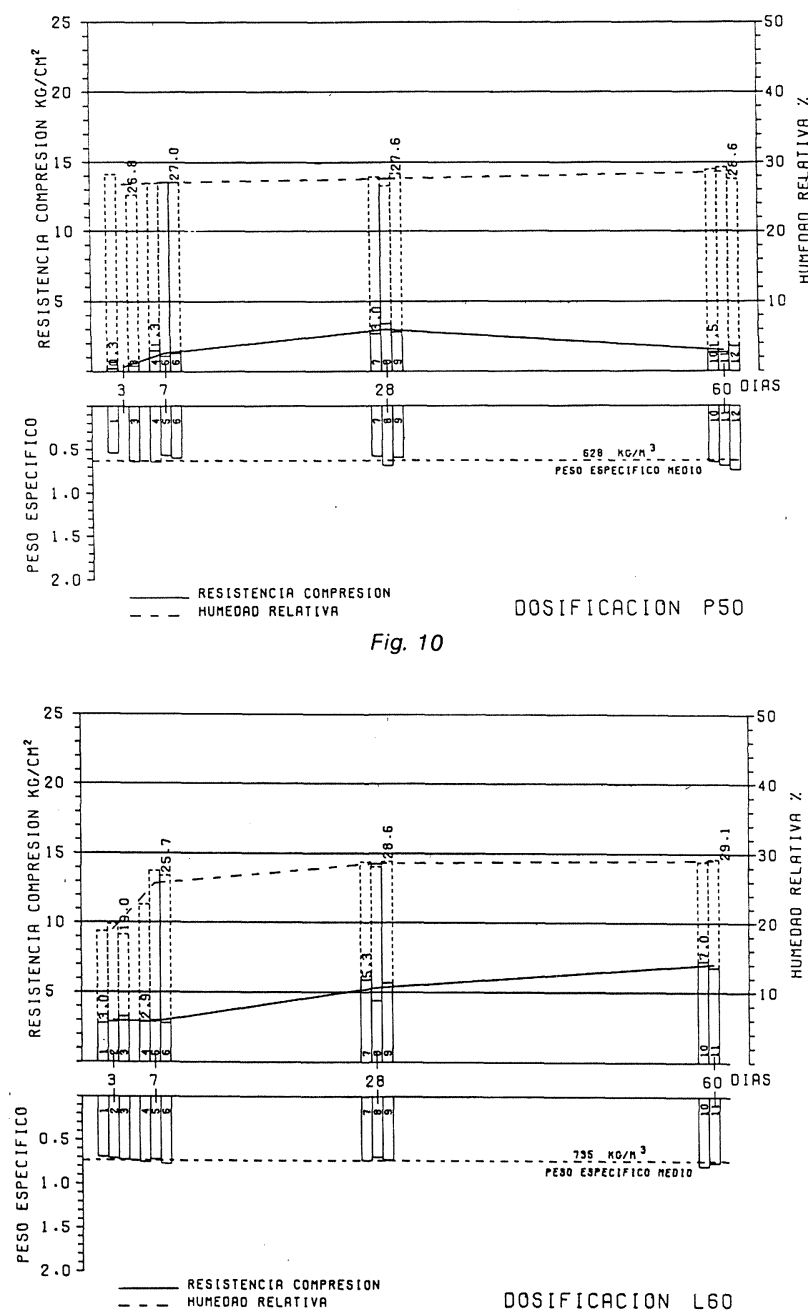

Fig. 11

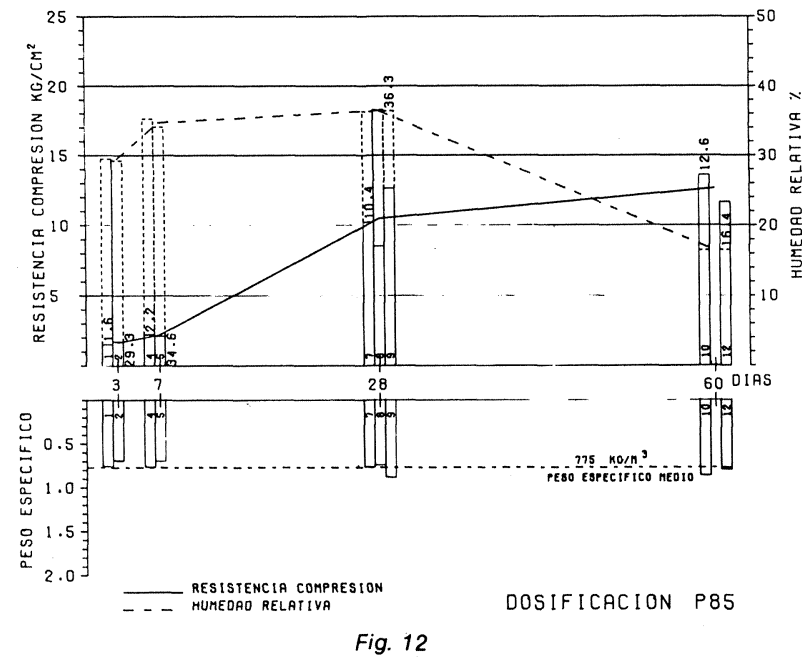

http://informesdelaconstruccion.revistas.csic.es 
$\mathrm{Al}$ igual que en los casos anteriores, en las figuras 10 a 15 se registran los valores medios de las series de tres probetas. De la figura 16, resumen de resultados, se deduce:

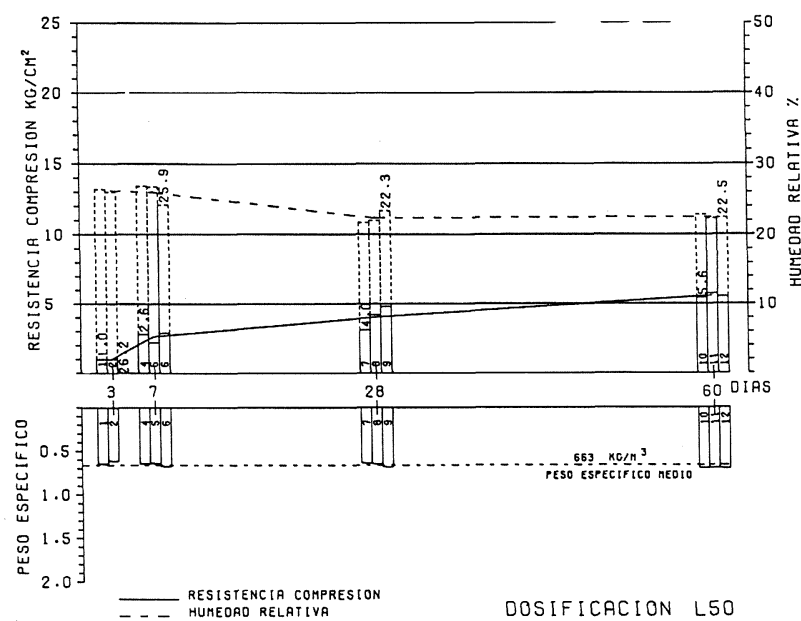

Fig. 13
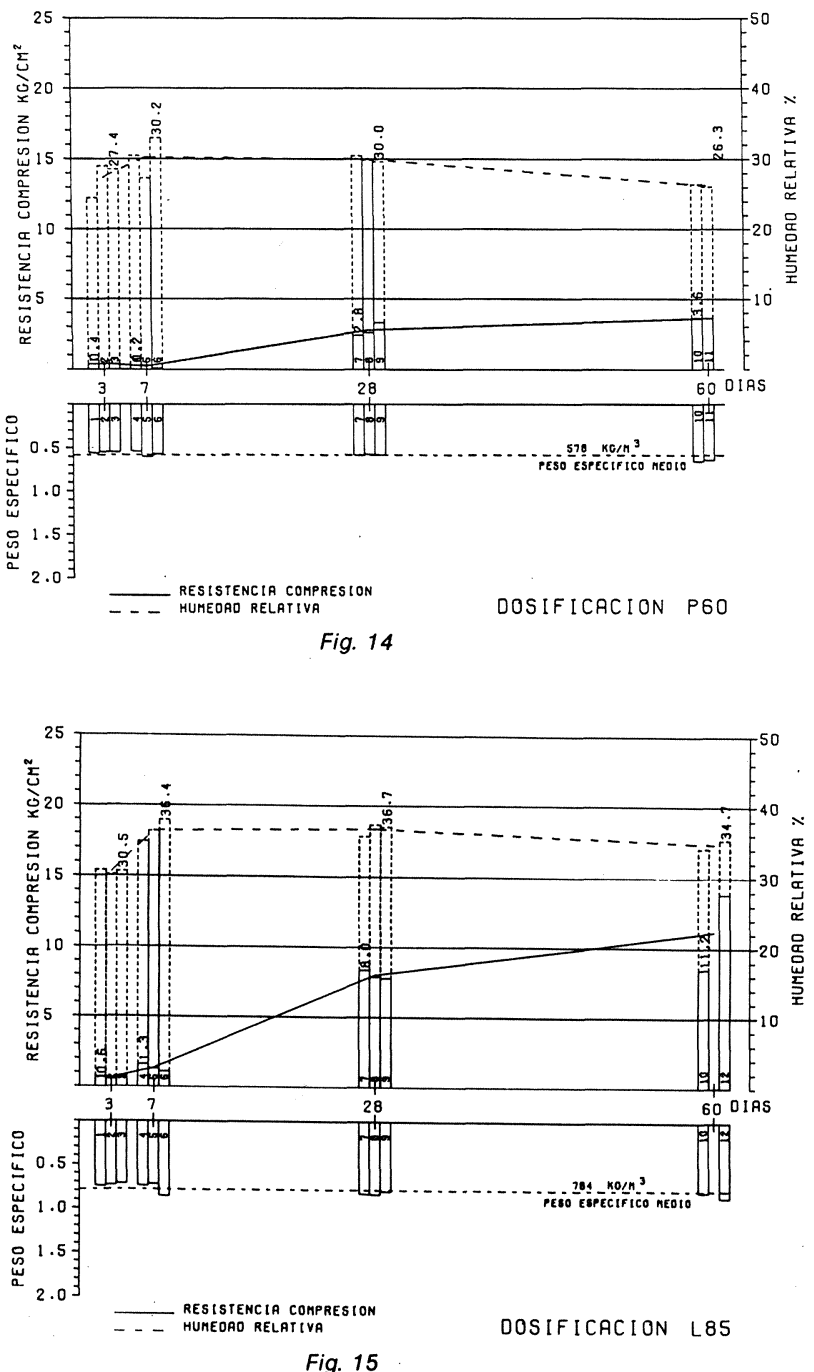

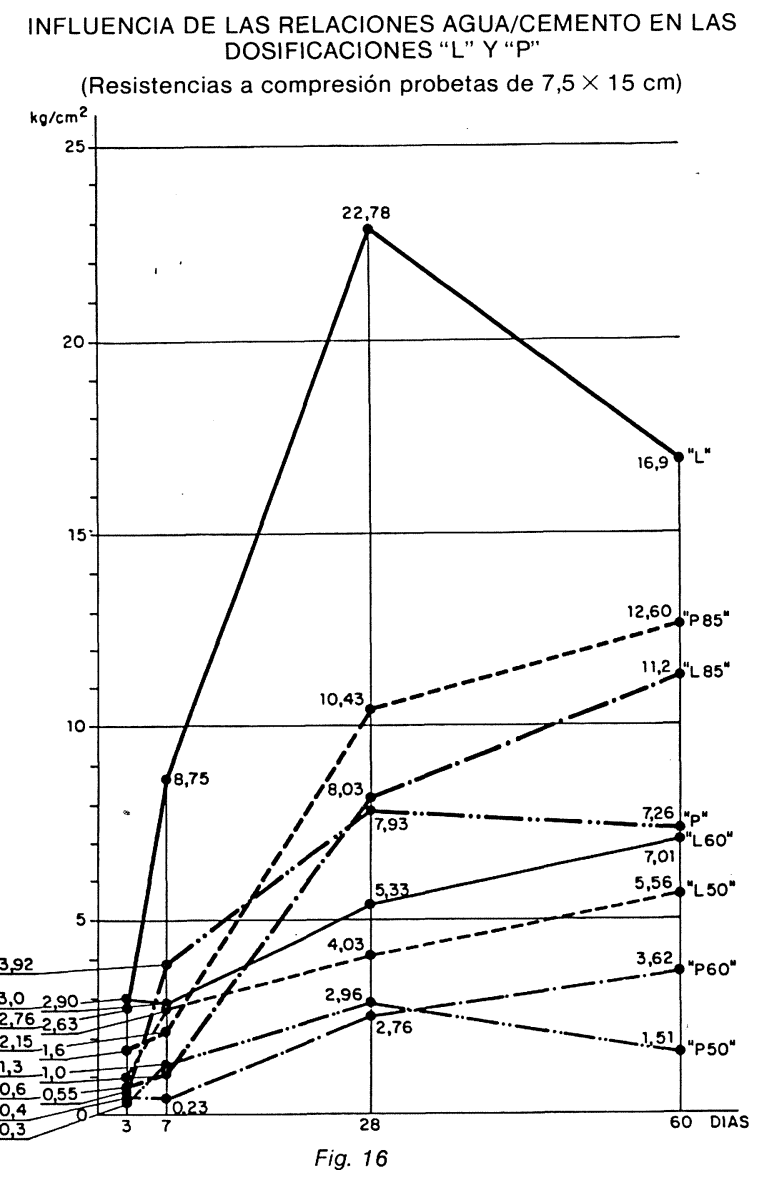

a) En todos los casos de dosificaciones «P», se producen incrementos de resistencias a compresión al aumentar las relaciones agua/cemento desde $0,50,0,60,0,75$ a 0,85 . Resulta por tanto aconsejable el adoptar la «P85» como la más conveniente a reserva de ensayar dosificaciones con relaciones agua/cemento superiores aún.

b) En las dosificaciones «L» (cáscara tratada), la que proporciona mejores resultados es la adoptada como patrón «L», de relación agua/cemento 0,75 .

c) Resultan dignas de mencionarse las caídas de resistencias después de los 28 días de permanencia en la cámara de curado en las dosificaciones: $\mathrm{L}$ P y P50.

\section{REALIZACION DE PANELES DE DOSIFICACIONES «PATRON» $\mathrm{y} « L »$ : ENSAYO A FLEXION}

En molde metálico y mediante compactación manual se realizaron paneles de $90 \times 60 \times 6 \mathrm{~cm}$ que permanecian en el molde, en el ambiente de la nave de hormigonado, durante tres dias; a los 28 dias se ensayaron a flexión simple apoyado en los extremos por peso propio (ver esquema, Fig. 17), tomándose mediante los tres flexímetros señalados las flechas en los tercios y el centro, cada dos dias. 
Al estabilizarse las flechas, se procedió a ensayar con carga repartida por escalones de $10,80 \mathrm{~kg}$, equivalente a $20 \mathrm{~kg} / \mathrm{m}^{2}$ con los resultados que se recogen en las Tablas 7 y 8 .

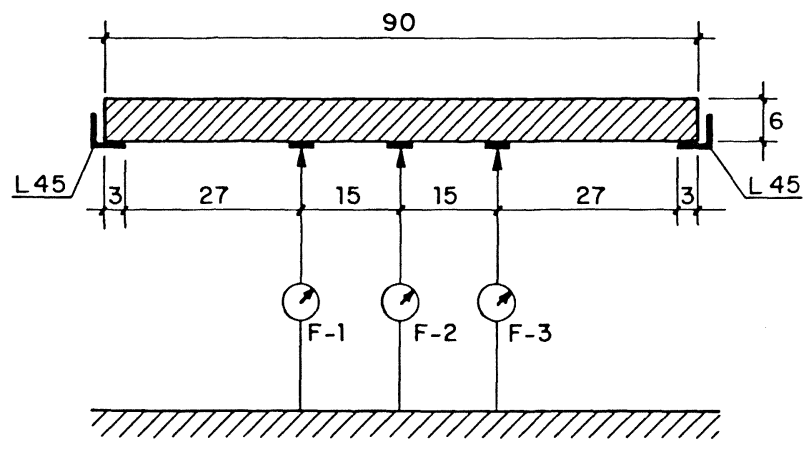

Fig. 17

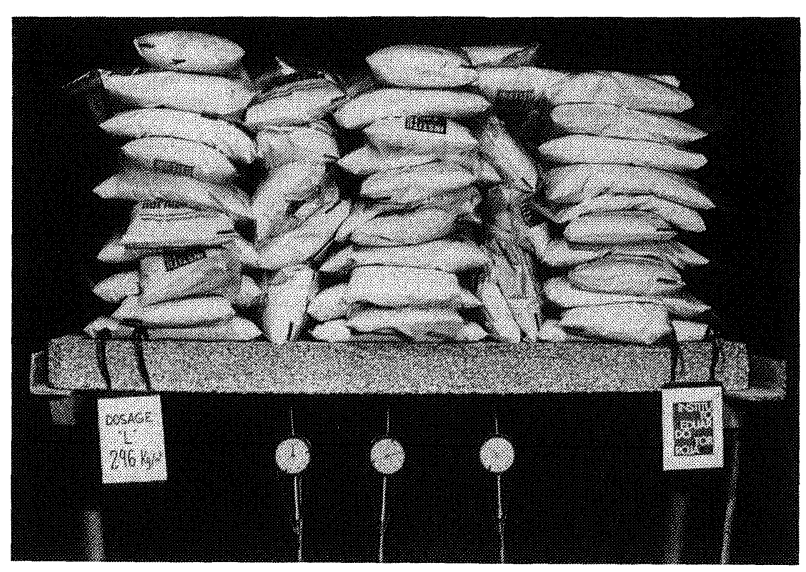

Fig. 18

Tabla 7

PANEL DE DOSIFICACION «PATRON» Dimensiones: $90 \times 60 \times 6 \mathrm{~cm}$ (Luz libre $870 \mathrm{~mm}$ ) Flechas medidas cada dos dias

\begin{tabular}{|l|r|r|r|r|}
\hline \multirow{2}{*}{ Carga } & \multicolumn{3}{|c|}{ Valores medidos en mm } & Relación \\
\cline { 2 - 4 } & F1 & \multicolumn{1}{c|}{ F2 } & \multicolumn{1}{c|}{ F3 } & F/luz \\
\hline Peso propio & 0,00 & 0,00 & 0,00 & $1 / 200$ \\
& 3,86 & 4,36 & 4,20 & \\
\hline $20 \mathrm{~kg} / \mathrm{m}^{2}$ & 7,47 & 8,37 & 7,73 & $1 / 104$ \\
& 12,72 & 14,23 & 12,83 & $1 / 67$ \\
\hline $40 \mathrm{~kg} / \mathrm{m}^{2}$ & 13,52 & 15,15 & 13,64 & $1 / 57$ \\
& 14,64 & 16,42 & 14,91 & $1 / 53$ \\
\hline $60 \mathrm{~kg} / \mathrm{m}^{2}$ & 15,40 & 17,30 & 15,49 & $1 / 50$ \\
& 17,34 & 18,38 & 16,40 & $1 / 47$ \\
\hline $80 \mathrm{~kg} / \mathrm{m}^{2}$ & 17,38 & 19,62 & 17,45 & $1 / 44$ \\
& & ROMPIO & & \\
\hline
\end{tabular}

Tabla 8

PANEL DE DOSIFICACION «L» Dimensiones: $90 \times 60 \times 6 \mathrm{~cm}$ (Luz libre $870 \mathrm{~mm}$ ) Flechas medidas cada dos días

\begin{tabular}{|l|c|c|c|c|}
\hline \multirow{2}{*}{ Carga } & \multicolumn{3}{|c|}{ Valores medidos en mm } & Relación \\
\cline { 2 - 5 } & F1 & F2 & F3 & (luz \\
\hline Peso propio & 0,63 & 1,52 & 0,61 & $1 / 592$ \\
\hline $20 \mathrm{~kg} / \mathrm{m}^{2}$ & 0,05 & 0,68 & 0,03 & $1 / 1323$ \\
\hline $40 \mathrm{~kg} / \mathrm{m}^{2}$ & 0,04 & 0,68 & 0,03 & $1 / 1323$ \\
\hline $60 \mathrm{~kg} / \mathrm{m}^{2}$ & 0,23 & 0,88 & 0,23 & $1 / 1023$ \\
\hline $280 \mathrm{~kg} / \mathrm{m}^{2}$ & 3,02 & 3,92 & 2,93 & $1 / 222$ \\
\hline $300 \mathrm{~kg} / \mathrm{m}^{2}$ & 3,19 & 4,13 & 3,09 & $1 / 210$ \\
\hline $360 \mathrm{~kg} / \mathrm{m}^{2}$ & 3,93 & 5,07 & 3,85 & $1 / 172$ \\
\hline $420 \mathrm{~kg} / \mathrm{m}^{2}$ & 4,65 & 6,72 & 4,42 & $1 / 129$ \\
\hline
\end{tabular}

El panel con dosificación «patrón» rompió para una sobrecarga repartida de $80 \mathrm{~kg} / \mathrm{m}^{2}$, midiéndose antes de la rotura una flecha en el centro de $19,62 \mathrm{~mm}$, equivalente a una relación flecha/luz de 1/44.

De forma semejante a la descrita se procedió con un elemento de dosificación "L», anotándose los datos que se recogen en la Tabla 8 . El panel rompió para una sobrecarga repartida de $420 \mathrm{~kg} / \mathrm{m}^{2}$, midiéndose antes de la rotura una flecha en el centro de $6,72 \mathrm{~mm}$, equivalente a una relación flecha/luz de 1/129. (Ver Fig. 18 correspondiente a un estado intermedio de carga).

\section{DETERMINACION DE LOS COEFICIENTES DE CONDUCTIVIDAD DEL MATERIAL}

Por razones de la instrumentación empleada por el equipo del IETcc que trabaja en el proyecto «Ahorro de Energía en Edificación», para la determinación del coeficiente de conductividad, se ejecutaron placas de $60 \times 60 \times 6 \mathrm{~cm}$ con las dosificaciones «P» $\mathrm{y}$ «L». Al objeto de facilitar la manipulación de las placas se procedió a dar una lechada de mortero en el fondo del molde y otra en la cara superior de las placas de aproximadamente $5 \mathrm{~mm}$ de espesor. Los elementos permanecieron 3 dias en los moldes, procediendo a determinar la estabilización de peso mediante estufa.

El ensayo de medida del flujo térmico se realizó en todos los casos entre 30 y $10{ }^{\circ} \mathrm{C}$ para las caras caliente y fría respectivamente, mediante equipo «R-Matic» diseñado conforme a la norma ASTM C518. (Ver tabla 9). 
Tabla n.o 9

\begin{tabular}{|c|c|c|c|c|c|c|c|c|}
\hline Dosificación & $\begin{array}{c}\text { kg } \\
\text { Peso del } \\
\text { elemento }\end{array}$ & $\begin{array}{c}\text { Peso } \\
\text { estabilizado } \\
\text { del elemento }\end{array}$ & $\begin{array}{l}\text { Absorción } \\
\text { de agua } \\
\text { (\%) }\end{array}$ & $\begin{array}{c}\left(\mathrm{kg} / \mathrm{m}^{\mathbf{3}}\right) \\
\text { Peso especifico } \\
\text { seco }\end{array}$ & $\begin{array}{c}\text { Espesor } \\
\text { e } \\
(\mathbf{m m})\end{array}$ & $\begin{array}{c}\text { Conductividad } \\
\text { térmica } \\
\lambda\end{array}$ & $\begin{array}{c}\text { Resistencia } \\
\text { térmica } \\
\mathbf{R}=\mathbf{e} / \lambda\end{array}$ & $\begin{array}{c}\text { Transmisión } \\
\text { térmica } \\
K=1 / R\end{array}$ \\
\hline «Patrón» & 17,480 & 15,321 & 12,35 & 653,57 & 63,00 & 0,1055 & 0,5975 & 1,6736 \\
\hline «L» & 20,468 & 18,696 & 8,66 & 824,33 & 62,07 & 0,1230 & 0,505 & 1,980 \\
\hline
\end{tabular}

NOTA: Valores medios de series de tres medidas.

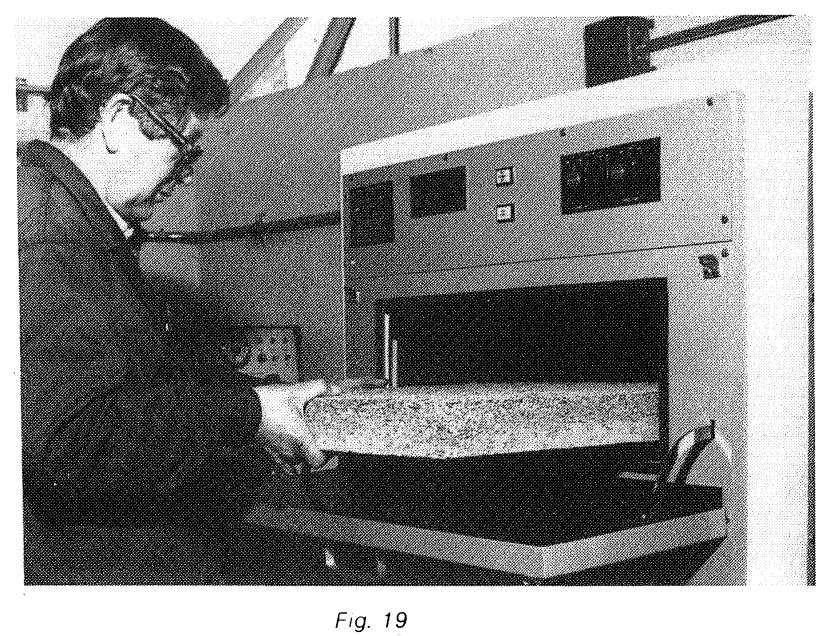

Se tomaron tres medidas en intervalos de $30^{\prime}$ cada una y se anotaron los respectivos valores de cada medición, determinándose el valor medio de la serie de tres placas para el coeficiente de conductividad $(\lambda)$ y la resistencia térmica interna que resultaron ser las siguientes:

\begin{tabular}{|c|c|c|}
\hline Dosificación & $\begin{array}{c}\text { Valor Medio } \\
\lambda\left(\mathbf{W} / \mathbf{m}^{\mathbf{}} \mathbf{C}\right)\end{array}$ & $\begin{array}{c}\text { Valor Medio } \\
\mathbf{R}\left(\mathbf{m}^{\mathbf{2}} \mathbf{}{ }^{\mathbf{C}} / \mathbf{w}\right)\end{array}$ \\
\hline Patrón & 0,1055 & 0,5975 \\
«L» & 0,123 & 0,5050 \\
\hline
\end{tabular}

El valor de la constante $\mathrm{N}$ de calibración del aparato para una temperatura de $20{ }^{\circ} \mathrm{C}$ se tomó igual a $0,1560 \mathrm{~W} / \mathrm{m} . \mathrm{cm} . \mathrm{mV}$. (Ver Fig. 19).

\section{COEFICIENTE DE CORRECCION DE RESISTENCIAS ENTRE PROBETAS}

Al objeto de determinar la posible equivalencia o coeficientes de transformación entre los valores de las resistencias obtenidas entre probetas de $7,5 \times 15,0 \mathrm{~cm}$ y de $15 \times 30 \mathrm{~cm}$, se realizaron, utilizando idénticas amasadas de dosificación "patrón» para ambos tipos, el mismo curado y compactación por barra, en ambos casos, dos series de probetas cuyos resultados se recogen en la Tabla 10 y en la figura 20.
Tabla n.o 10

\begin{tabular}{|c|c|c|c|}
\cline { 2 - 4 } \multicolumn{1}{c|}{} & $\begin{array}{c}\text { Prob. 7,5 } \times 15 \\
\text { Resistencia } \\
\text { media }\end{array}$ & $\begin{array}{c}\text { Prob. } 15 \times 30 \\
\text { Resistencia } \\
\text { media }\end{array}$ & $\begin{array}{c}\text { Coeficiente de } \\
\text { transformación } \\
\text { de 7,5 } \times \mathbf{1 5} \text { a 15,30 }\end{array}$ \\
\hline A 3 dias & 0,56 & 3,30 & 0,169 \\
\hline A 28 dias & 7,93 & 2,72 & 2,915 \\
\hline A 60 dias & 7,26 & 5,43 & 1,337 \\
\hline
\end{tabular}

DOSIFICACION PATRON

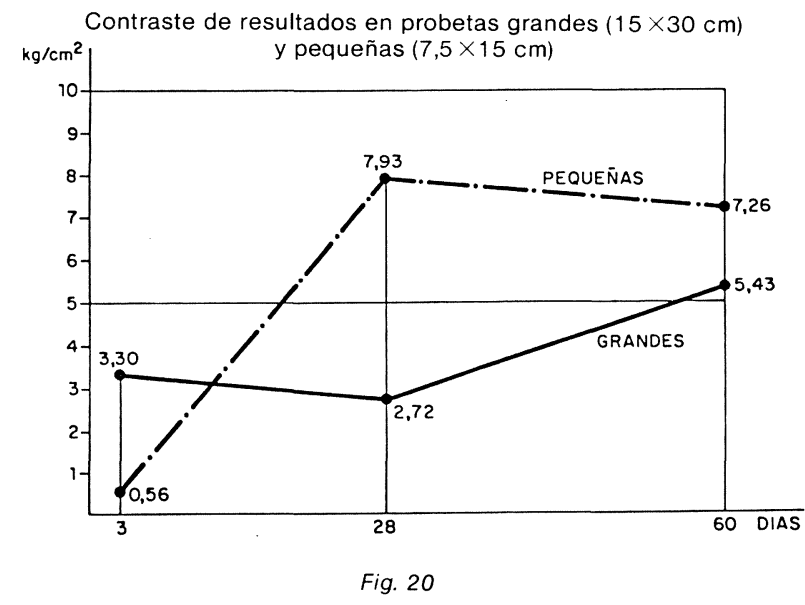

En base a los datos aludidos resulta muy problemático el establecer, con cierta fiabilidad, unos coeficientes de transformación válidos, ya que la disparidad de la tendencia es absoluta. Se evidencia la necesidad de profundizar en el tema.

\section{PERDIDA DE PESO AL FUEGO}

Una muestra de material, dosificación "patrón», aproximadamente cúbica de $6 \times 6 \times 6 \mathrm{~cm}$ y un peso de $119,65 \mathrm{~g}$, se ha sometido a incrementos de temperatura de $100{ }^{\circ} \mathrm{C}$ desde la temperatura ambiente hasta $1.000{ }^{\circ} \mathrm{C}$, mediante horno. En el transcurso del ensayo se han determinado los pesos de la muestra y se han anotado referencias sobre el aspecto. 
Por encima de $200{ }^{\circ} \mathrm{C}$ el peso y la forma externa prácticamente se mantienen, aunque no la resistencia. En la Tabla 11 y figura 21 se recogen los resultados del ensayo.

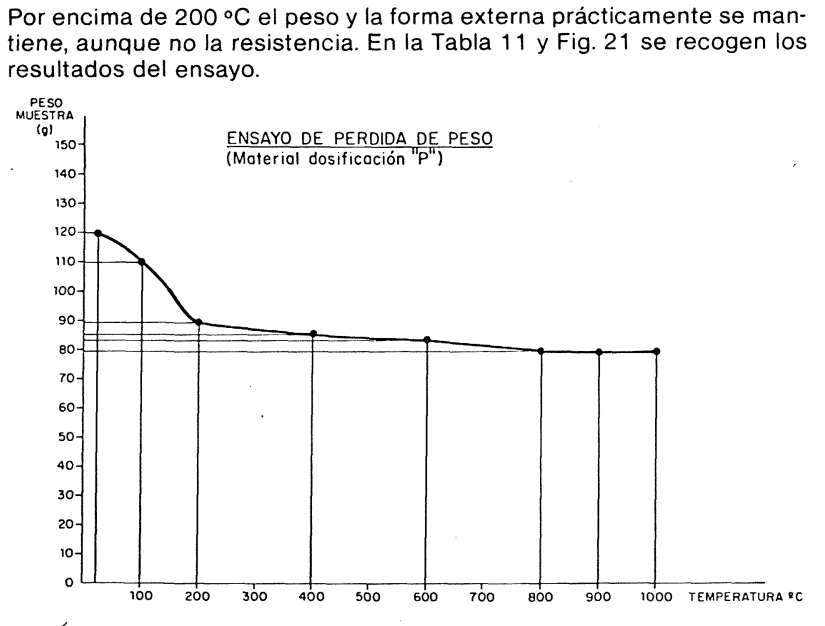

Fig. 21

Tabla n.o 11

COMPORTAMIENTO DE UNA MUESTRA AL VARIAR LA TEMPERATURA

\begin{tabular}{|c|c|l|}
\hline Temperatura & $\begin{array}{c}\text { Peso de la } \\
\text { muestra }\end{array}$ & \multicolumn{1}{|c|}{ Aspecto } \\
\hline T ambiente & $119,65 \mathrm{~g}$ & $\begin{array}{l}\text { La muestra tiene forma cúbica, } \\
\text { su color es grisáceo. }\end{array}$ \\
\hline $100{ }^{\circ} \mathrm{C}$ & $110,39 \mathrm{~g}$ & $\begin{array}{l}\text { La nuestra tiene forma cúbica, } \\
\text { su color es grisáceo. }\end{array}$ \\
\hline $200{ }^{\circ} \mathrm{C}$ & $89,45 \mathrm{~g}$ & $\begin{array}{l}\text { La nuestra tiene forma cúbica, } \\
\text { su color es grisáceo. }\end{array}$ \\
\hline $400{ }^{\circ} \mathrm{C}$ & $86,05 \mathrm{~g}$ & $\begin{array}{l}\text { La forma se mantiene, pero e } \\
\text { color se vuelve más oscuro. }\end{array}$ \\
\hline $600{ }^{\circ} \mathrm{C}$ & $84,04 \mathrm{~g}$ & $\begin{array}{l}\text { Cuando se presiona la muestra } \\
\text { se deshace. }\end{array}$ \\
\hline $800{ }^{\circ} \mathrm{C}$ & $79,80 \mathrm{~g}$ & $\begin{array}{l}\text { Cuando se presiona la muestra } \\
\text { se deshace. }\end{array}$ \\
\hline $900{ }^{\circ} \mathrm{C}$ & $79,47 \mathrm{~g}$ & $\begin{array}{l}\text { Cuando se presiona la muestra } \\
\text { se deshace. }\end{array}$ \\
\hline $1.000^{\circ} \mathrm{C}$ & $79,39 \mathrm{~g}$ & $\begin{array}{l}\text { Cuando se presiona la muestra } \\
\text { se deshace. }\end{array}$ \\
\hline
\end{tabular}

\section{BIBLIOGRAFIA}

1. Mehta, P. K., y Pitt, N.: «A New Process of Rica Husk Utilization», Proceedings of the "Rice Husk Utilization», Valencia (CSIC), 1974.

2. Borasio, G.: «Analysis of Rice husk ash», Risicoltura, Roma, Italia, 1928.

3. Ojha, T. P.; Maheshwary, R. C., y Shukla, B. D.: «Optimizing technologies of rices husk utilization as source of fuel and industrial board». International Conference, Valencia, 1974.

4. Francesco Bennuti: «Aprovechamiento Industrial de Productos Agrícolas», Ingeominas, 1974.

5. Lemus, V.; López, H., y Olvera, H.: «Materiales a base de deshechos agrícolas e industriales", Informes de la Construcción n. ${ }^{\circ}$ 344-345, Noviembre, 1982.

6. Aguirre, J. A., y Sierra, P. F.: «Uso de la cascarilla de arroz como aligeramiento y su ceniza como aditivo en el hormigón». Universidad Nacional de Colombia, Departamento de Ingenieria Civil, 1980.

* Moha, D.; Rai, M., and Relipi, S. S.: «Industrial wastes and building materials». V. N. Seminar on the Use of Industrial and Agricultural Wastes for how Cost Construction, Puerto Rico, dec., 1974.

* Singh, S. M.: "Agro-industrial wastes and their utilization". Research and Industry 19, n. ${ }^{\circ} 4,1974$.

* Vasishth, R. C. and Chandramouli, P.: «New panel boards from rice husks and other agricultural by products». Background Paper n.o 30, FAO, New Delhi. Feb., 1975.

* Datta, R. K., and Dass, K.: «Use of rice husk in building materials». Seminar on Rice Mill Modernization, East India Rice Mills Assoc., Calcuta. Sep., 1974.

* Stackman, M., and others: «Rice hull utilization». Final Report. URS Research Co. California. Sep., 1970.

* Coté, W. A.: «Rice husk characterization using SEM and EDXA». J. Indian Acad. Wood. Sci. 5, n. ${ }^{\circ} 1$ (1974).

* Singh, S. M., and Aggarwal, L, K.: «Portland cement bonded panel products from agricultural wastes». Research and Industry 22 , n. ${ }^{\circ} 4,242-245$ (1977).

* George, J.; Zoolagud, S. S., and Jagadeesh, H. N.: «New building materials from rice husk production, properties and application». National Seminar. Trivandrum, India. Sept., 1976.

* Chaudramouli, P.: «Comparative properties of rice husk board, partide board and wafer board. Interim Report». Cor. Tech. 2, 1973. 